\title{
Change in Sustainable Economies
}

\author{
Frederick Betz ${ }^{1,2}$ \\ ${ }^{1}$ Department of Technology and Society, SUNY Korea, Seoul, Korea \\ ${ }^{2}$ Department of Engineering and Technology Management, Portland State University, Portland, Oregon, USA \\ Correspondence: Frederick Betz, Department of Technology and Society, SUNY Korea, Seoul, Korea. E-mail: \\ fbetz@venture2reality.com
}

Received: December 10, 2014 Accepted: February 16, 2015 Online Published: March 30, 2015

doi:10.5539/jsd.v8n2p73 URL: http://dx.doi.org/10.5539/jsd.v8n2p73

\begin{abstract}
Two important problems in models for a sustainable economy are (1) how to connect environmental models with societal models and (2) how to model the impact of societal changes upon an environment.For the first challenge, the Leontief economic model has been transformed from a vector to a tensor equation, as a model for integrating regional descriptions of an economy and its local environment. However, this is a static model of a steady-state (stasis) economy during a given period; and here we address the second challenge of modeling the impact of societal change upon an economy and its environment.We apply the modeling of societal change in the historical case of Australia's Mining Rent Tax of 2012-2014.
\end{abstract}

Keywords: sustainable economy, environmental models, societal models

\section{Introduction}

Every model has a specific form, specific dynamics, specific content, and specifically formatted data input and information output. This is especially true of economic models, measuring economic activities in prices and monetary values, compared to environmental models, measuring natural processes in terms of physical and/or biological forms - money versus nature.

A model for a societal environment (e.g. an economy) needs to be represented in functional relations prescriptive.A model for a physical environment is represented in causal mechanisms - causality.Thus different kinds of models need 'translations', or 'ontology' to exchange information. The concept of a 'model ontology' (as analogous to the idea of 'data ontology' in computer science) was proposed in order to deal with the complications of communicating information between different types of models.(Betz and Phillips, 2012)This emphasizes the importance of formulating models of complex things (such as societal and environmental systems) so that information can be exchanged between models.In a 'data ontology', one has shared dictionaries for communication of quantitative variables over the Internet.In a 'model ontology', one must have shared methodologies for models to communicate with each other.We also examine a 'model ontology' for communicating the effect of changes in political-economic systems onto environmental systems.

Attempting to combine two such different models within a larger, more complete model can create a complexity in modeling and data management which can be obscure, oversimplifying, and inaccurate for a model of a whole system. Thus efficient and accurate models must always be of appropriate perspective and of a finite size, tested and validated with observable data. A modeling methodology needs to have its detail, 'graininess', appropriate to the realistic challenge.We address the 'graininess' issue in modeling for sustainable economy by 'regionalizing' an integrated economic-environmental model.

\section{Background}

For economic and environmental policies aimed at developing sustainable economies, it is important to have a modeling approach which can quantitatively connect economic processes with biological and physical processes of the environment.If economic processes cannot be measured as to their real physical/biological impacts, one does not know whether or not such economic processes are sustainable in nature.

The author had extended the Leontief economic model to connect to environmental models. (Betz, 2013)Wassily Leontief formulated an economic model of national economy as an input-output balance of products produced and consumed.(Leontief, 1968)The production (P) from an economic sector consists of the sum of the I-th 
products $\mathbf{P}_{\mathbf{I}}$ produced in the region $\left(\mathbf{P}=\Sigma_{\mathbf{I}} \mathbf{P}_{\mathbf{I}}\right)$. Leontief traced the quantity of production $\mathbf{P}_{\mathbf{I}}$ of an I-th production into the distribution in the economy for consumers $\left(\mathbf{C}_{\mathbf{I}}\right)$ or for other J-th industrial sectors $\left(\mathbf{X}_{\mathbf{I J}}\right)$ or exported to other K-th countries $\left(\mathbf{E}_{\mathbf{j K}}\right)$ or imported $\left(\mathbf{I}_{\mathbf{I K}}\right)$ from other K-th countries. An input-output economic model for a region is a vector equation:

$\mathbf{P}_{\mathbf{I}}+\Sigma_{\mathbf{K}} \mathbf{I}_{\mathrm{IK}}=\mathbf{C}_{\mathbf{I}}+\Sigma_{\mathrm{J}} \mathbf{X}_{\mathrm{IJ}}+\Sigma_{\mathrm{K}} \mathbf{E}_{\mathrm{IK}}$.

This reads that the quantity of production $\mathbf{P}_{\mathrm{I}}$ of the I-th product in an economic region plus the quantity of imports of the I-th product $\Sigma_{\mathbf{K}} \mathbf{I}_{\mathbf{I K}}$ is distributed to the regional consumers $\mathbf{C}_{\mathbf{I}}$ of the I-th products and to the sum of the regional industrial purchasers $\boldsymbol{\Sigma}_{\mathbf{J}} \mathbf{X}_{\mathbf{I J}}$ of the I-th product and to exports $\boldsymbol{\Sigma}_{\mathbf{K}} \mathbf{E}_{\mathbf{I K}}$ to all the K-th counties. The summation $\left(\Sigma_{\mathbf{J}}\right)$ is taken over all other J-th economic sectors, and the summations $\left(\boldsymbol{\Sigma}_{\mathbf{K}}\right)$ over all the other K-th nations.

Since Leontief's equation is a vector equation, it can be mathematically generalized to a tensor equation. Vectors have one index of notation (usually indicated by a subscript), and tensors have two indices of notation (usually indicated by a subscript and a superscript). Then the product vector $\left(\mathbf{P}_{\mathbf{I}}\right)$ with the I-th subscript can become a product tensor $\mathbf{P}_{\mathbf{I}}^{\mathbf{N}}$ with the I-th subscript and an $\mathbf{N}$-th superscript. In tensor notation, Leontief's equation becomes:

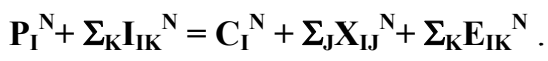

The reason for this generalization is that one can use the $\mathrm{N}$-th superscript to denote $\mathrm{N}$ different planes of processes in a region. One can use $\mathrm{N}=1$ to denote Leontief's economic plane of the region and $\mathrm{N}=2$ to denote the physical-biological environmental plane of the region:

$$
\begin{array}{cc}
\mathbf{P}_{\mathbf{I}}{ }^{1}+\Sigma_{\mathbf{K}} \mathbf{I}_{\mathbf{I K}}{ }^{1}=\mathbf{C}_{\mathbf{I}}{ }^{1}+\Sigma_{\mathbf{J}} \mathbf{X}_{\mathbf{I J}}{ }^{1}+\Sigma_{\mathbf{K}} \mathbf{E}_{\mathbf{I K}}{ }^{1} & \text {-- the economic plane } \\
\mathbf{P}_{\mathbf{I}}{ }^{2}+\Sigma_{\mathbf{K}} \mathbf{I}_{\mathbf{I K}}{ }^{2}=\mathbf{C}_{\mathbf{I}}{ }^{2}+\Sigma_{\mathbf{J}} \mathbf{X}_{\mathbf{I J}}{ }^{2}+\Sigma_{\mathbf{K}} \mathbf{E}_{\mathbf{I K}}{ }^{2} & \text {-- the environmental plane }
\end{array}
$$

These are shown as two parallel planes over a region in figure 1 .

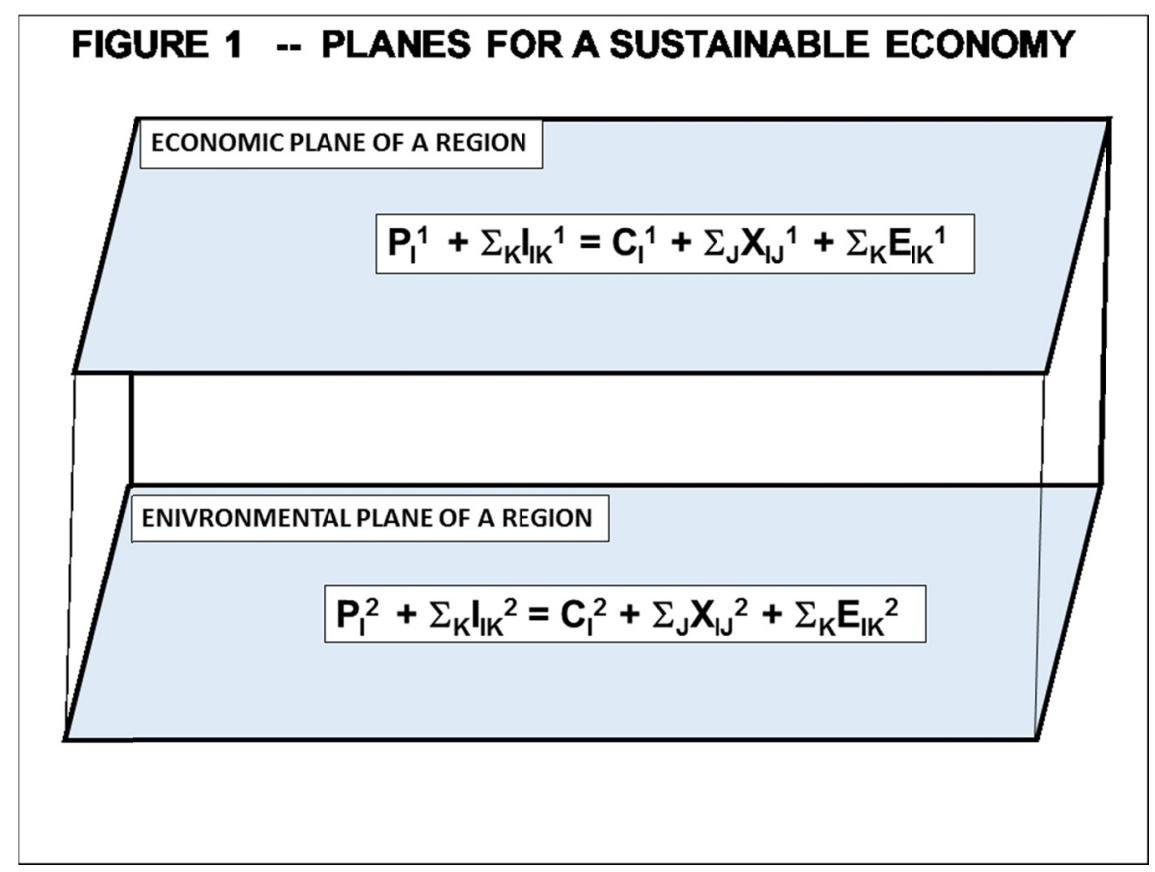

Figure 1. Planes for a sustainable economy

In the economic-plane-1, the tensor Leontief equation is a balance equation between economic supply and demand in a given time period. In the environmental-plane-w, the tensor Leontief equation is a balance equation between natural things in the same time period.Yet inthe environmental-plane-2, inanimate and animate natural things are not 'produced'; they are natural things existing and born or died.So the quantity $\mathbf{P}_{\mathbf{I}}^{2}$ of natural things are the inanimate or animate objects existing prior to the time period; and in the case of animate objects, $\mathbf{P}_{\mathbf{I}}^{2}$ also includes the beings born and dying in that period.

This means in an economic time period, the changes in the quantity $\mathbf{P}_{\mathbf{I}}^{\mathbf{2}}$ of physical/biological things in the 
environmental-plane-2 can also be:

Increased by things imported physically into that region from other K regions: $+\Sigma_{K} \mathbf{I}_{\mathbf{I K}}{ }^{2}$

Decreased by things taken physically from the region:- $\mathbf{C}_{\mathbf{I}}{ }^{2}$

Decreased by things used physically by other environmental processes of the region:- $\Sigma_{\mathrm{J}} \mathbf{X}_{\mathrm{IJ}}{ }^{2}$

Decreased by things exported physically from that region into other K regions:- $\Sigma_{\mathbf{K}} \mathbf{E}_{\mathbf{I K}}{ }^{2}$.

For example, topsoil may be mined or eroded, or a species may be exterminated.The quantity $\mathbf{X}_{\mathrm{IJ}}{ }^{2}$ is the amount of a thing involved in other processes in the environment $\mathrm{N}=2$.For example, rain feeds watersheds and also rivers in the physical environment.Or for example in biological processes, herbivores feed carnivores. The quantity $\mathbf{E}_{\mathbf{I K}}{ }^{2}$ expresses the amount of an I-th physical/biological thing exported from the regional environment into another region.For example, tributaries feed water from one region into a river in another region.

But also one may wish to express the exchanges of physical/biological things between the economic activities in plane-1 and the environmental processes in plane-2.Things from the environmental-plane-2 $(\mathrm{N}=2)$ into the economic-plane $1(\mathrm{~N}=1)$ are often natural resources used in the production and consumption activities of the economy of a region. We will denote this as the resource tensor: $\mathbf{R}_{\mathbf{G I}}{ }^{\mathbf{M N}}$.

On can define this quantity of resources $\mathbf{R}_{\mathbf{G I}}{ }^{\mathbf{M N}}$, where a G-th material/energy/biological resource from the environmental-plane-2 $(\mathrm{N}=2)$ is used in the economic-plane-1 $(\mathrm{M}=1)$ in the economic production of a unit of an I-th product.(We will use the superscript notation of 'to-from' as $\mathbf{R}_{\mathbf{G I}}{ }^{\mathbf{M}(\mathbf{t}) \mathbf{N}(\text { from })}$.) To calculate this quantity of G-th resource taken from the environmental plane, one can use the idea of a production function $\mathbf{R}^{\mathbf{G I}}{ }^{1}$, which is the quantity of G-th resource used to produce one unit of the I-th product. Then the quantity of the G-th resources used in producing $\mathbf{P}_{\mathbf{I}}{ }^{1}$ quantities of the I-th product is: $\mathbf{R}_{\mathrm{GI}}{ }^{12}=\mathbf{P}_{\mathbf{I}}{ }^{1} \mathbf{R}^{\prime}{ }_{\mathrm{GI}}{ }^{1}$. This quantity of resources is taken from the environmental plane-2, so that the quantity of the G-th material/energy is diminished from the environment.Thus the quantity of physical/biological things consumed $\mathbf{C}_{\mathbf{I}}{ }^{2}$ in the environmental-plane- 2 due to economic activities of economic-plane-1 are due to resource extraction activities. Thus one can set $\mathbf{C}_{\mathbf{I}}{ }^{2}=\mathbf{R}_{\mathrm{GI}}{ }^{12}$ and the environmental balance equation becomes: $\Delta \mathbf{P}_{\mathrm{I}}{ }^{2}=\Sigma_{\mathrm{K}} \mathbf{I}_{\mathrm{IK}}{ }^{2}-\mathbf{R}_{\mathrm{GI}}{ }^{12}-\Sigma_{\mathrm{J}} \mathbf{X}_{\mathrm{IJ}}{ }^{2}-\Sigma_{\mathrm{K}} \mathbf{E}_{\mathrm{IK}}{ }^{2}$; where $\Delta \mathbf{P}_{\mathrm{I}}{ }^{2}$ is the change in environmental things due to economic action in the region.

Also in the regional production and use of the I-th product in the economic-plane-1, there will be two kinds of waste created in that plane and sent into the environmental plane, a production waste and a consumption waste.The production waste $\mathbf{W}_{\mathbf{H I}}{ }^{\mathbf{2 1}}$ is the quantity of $\mathrm{H}$-th waste created in the economic production of the I-th products; and can be calculated from per-unit waste quantities as $\mathbf{W}_{\mathbf{H I}}{ }^{21}=\mathbf{P}_{\mathbf{I}}{ }^{1} \mathbf{W}^{\prime}{ }_{\mathbf{H I}}{ }^{21}$, where $\mathbf{W}^{\prime}{ }_{\mathbf{H I}}{ }^{21}$ is the industrial waste production function per unit quantity of the I-th product.The consumption waste $\mathbf{H}_{\mathbf{L I}}{ }^{21}$, which is the quantity of L-thwaste created in the regional consumption of the I-th products; and can be calculated from a per-unit consumption quantities as $\mathbf{H}_{\mathbf{L I}}{ }^{21}=\mathbf{P}_{\mathbf{I}}{ }^{1} \mathbf{H}_{\mathbf{L I}}{ }^{21}$.

The industrial waste $\mathbf{W}_{\mathbf{H I}}{ }^{21}$ and the consumption waste $\mathbf{H}_{\mathbf{L}}{ }^{21}$ areboth disposed into the environmental-plane-2, so the environmental input-output balance equation due to economic activities becomes:

$\Delta \mathbf{P}_{\mathrm{I}}^{2}=+\mathbf{W}_{\mathrm{HI}}{ }^{21}+\mathbf{H}_{\mathrm{LI}}{ }^{21}+\Sigma_{\mathrm{K}} \mathbf{I}_{\mathrm{IK}}{ }^{2}-\mathbf{R}_{\mathrm{GI}}{ }^{12}-\Sigma_{\mathrm{J}} \mathbf{X}_{\mathrm{IJ}}{ }^{2}-\Sigma_{\mathrm{K}} \mathbf{E}_{\mathrm{IK}}{ }^{2}$.

Figure 2 shows the integrated economic-environmental model in tensor form, as connections between a regional Leontief economic production model and a regional environmental market.This can provide a stasis model for modeling a sustainable economy. 


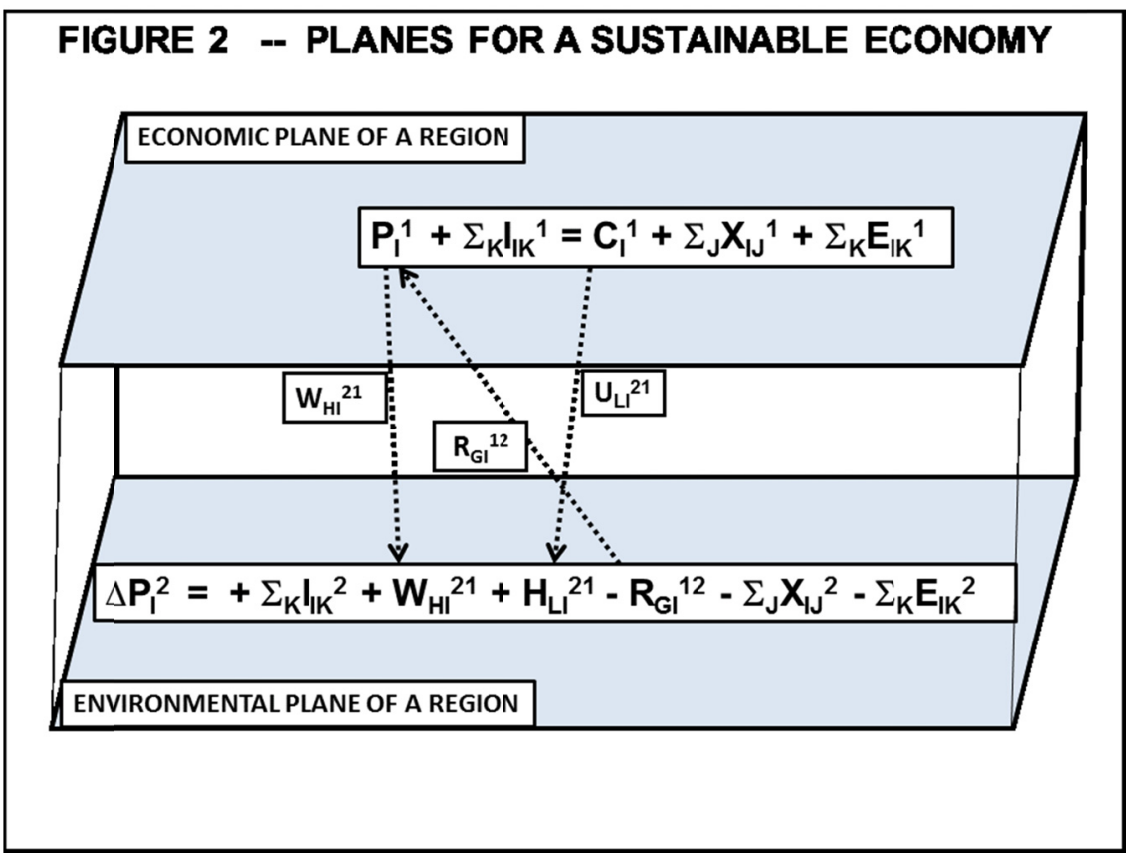

Figure 2. Planes for a sustainable economy

The advantage of this model is to capture both economic information and environmental information over the same territory (region) and to enable the expression of the impact of economic activities in the region upon the environment of the region.

\section{Historical Case: Australian Rent Mineral Tax Law 2012-14}

We now review a historical case of a societal decision which had impact upon environmental conditions in Australia, through the passage of mining-rent tax legislation in 2012.The quantity of $\mathbf{P}_{\mathbf{I}}{ }^{1}(\mathbf{t})$ iron ore mining would have been altered after 2012, by the governmental imposition of an additional tax on Australian mining companies profits (calledMinerals Resource Rent Tax Bill).Had the bill remained law, some impact upon the volume of iron ore mined $\mathbf{P}_{\mathbf{I}}{ }^{1}(\mathbf{t})$ would have happened over time (t).However, two years later in 2014 , a new Australian government repealed the tax.This is an interesting example of when a direct societal activity (government policy) would have made a direct environmental impact (extension of open pit mines).

In this case, the I-th index denotes the Australian mining industry; and $\mathbf{P}_{\mathbf{I}}{ }^{1}$ is the value of iron ore product produced in Australian annually. $\mathbf{R}_{\mathbf{G I}}{ }^{12}$ is the physical quantity of iron ore mined annually from the Australian earth. $\mathbf{W}_{\mathbf{H I}}{ }^{21}$ is the quantity of ore waste left in the environment. This model depicts how the economic activities of mining in Australia alters some of that landscape, with the quantity of iron ore removed directly deepening the mining pit, left after the open-pit mining technology.

One can add a temporal dimension to the equation to indicate the time period of the processes as: $\mathbf{P}_{\mathbf{I}}^{\mathrm{N}}(\mathbf{t})+$ $\Sigma_{K} I_{I K}{ }^{N}(t)=C_{I}^{N}(t)+\Sigma_{J} X_{I J}^{N}(t)+\Sigma_{K} E_{I K}^{N}(t)$. And the case focuses upon two periods:(1) the passage of the 'rent tax' on Australian mining in $\mathrm{t}=2012$ and (2) the repeal of the tax at $\mathrm{t}=2014$.

Mining always has a direct impact upon altering the environment, particularly with open-pit mining technology.Moreover, mining is a major industry in the world, providing materials for industrial production.As natural resources, mines are localized where geological processes had concentrated minerals.For the most part, large global companies mine for materials and own the mineral resources.Figure 3 shows an open-pit mine in Australia. 


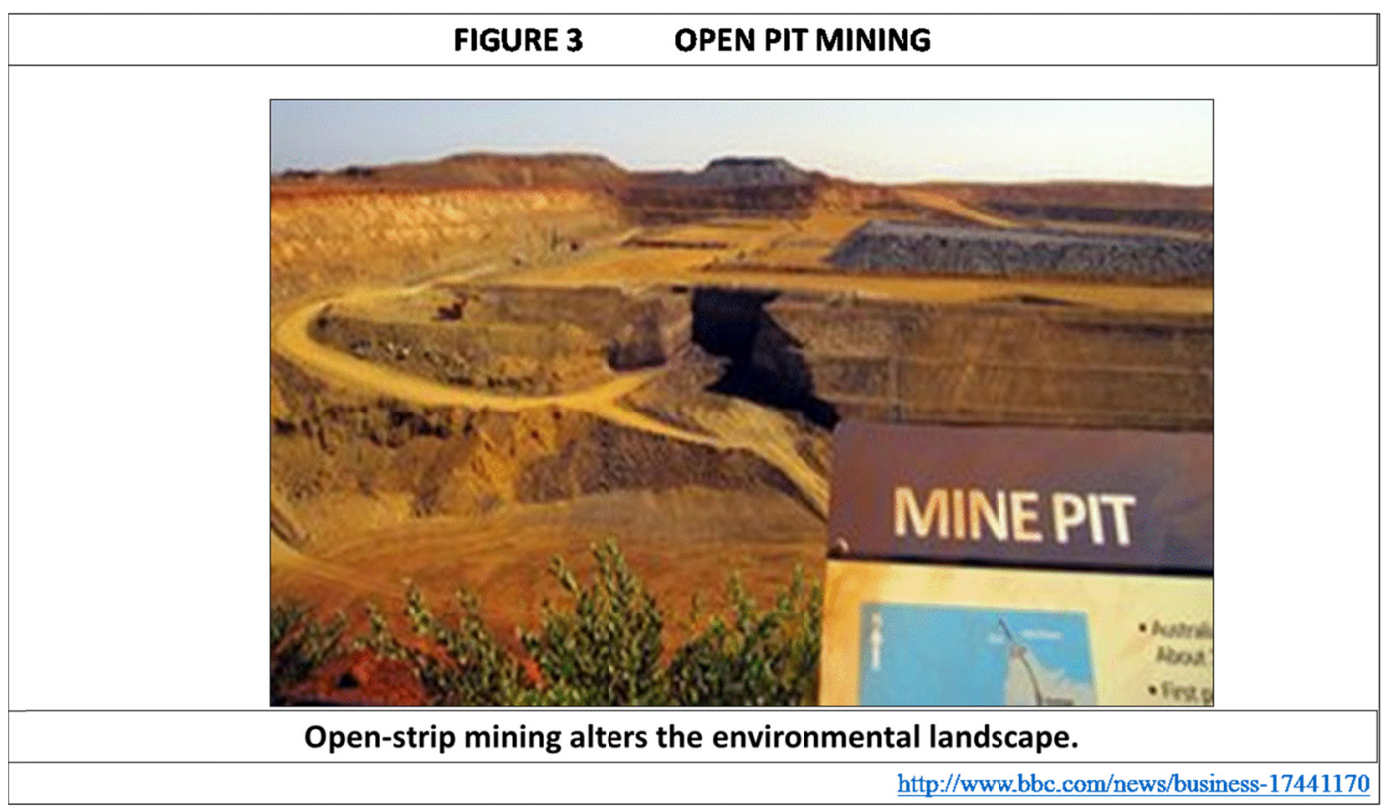

Figure 3. Open pit mining

In the Australian case, one of the companies impacted by the new tax would have been Rio Tinto. In 2014, Stanley Reedaug wrote about the company:"Rio Tinto, the London-based mining giant, said on Thursday that its first-half-year profit more than doubled to $\$ 4.4$ billion as the company shrugged off a sharp drop in iron ore prices, and reported improvements in its smaller aluminum and copper mining businesses.Despite evidence of a slowdown in the growth of steel production in China, Rio Tinto's crucial market, the company is sticking with plans to bolster the capacity of its iron ore mines in the Pilbara region of Western Australia by almost one-quarter by the middle of next year. That follows a roughly 20 percent expansion completed this year.The company is betting that its low Australian mining costs will allow it to thrive and squeeze out other producers with higher costs regardless of the price of iron ore.Sam Walsh, Rio Tinto's chief executive, said the company was "unapologetic" about continuing to focus investments on its iron ore unit, which accounts for about 90 percent of its profits, despite the nearly 30 percent drop in the price over the last year. . . 'High-cost producers are leaving the market,' Mr. Walsh told reporters during a conference call. He said that 'the fundamentals for iron ore remain strong." (Reedaug, 2014)

The amount of mined ore entering the market in any year is not only dependent upon the ore available (natural resources) but upon the demand and price of the ore (economics) in a given year.Thus changes to the environment (amount of ore mined and environmental pollution due to mining) varied from year to year dependent upon the economics and capacity.

In the Australian case during that period from 2012 to 2014, there was, in addition to economic market changes, political changes about taxes -- which could alter the mining operations and its impact upon the environment.The Australian government in 2012 added a mining tax on Australian mining companies' profits.BBC News reported:"The Australian government's plan to impose a 30\% tax on big mining companies has cleared a major hurdle, passing through parliament's lower house (in 2011).It will go to the upper senate early next year, but is expected to pass.The government said the tax was a way to distribute wealth more evenly from Australia's resources boom.It will go into effect in July 2012, and will apply to mining giants such as Rio Tinto and BHP Billiton.The Minerals Resource Rent Tax Bill will tax coal and iron profits. When the tax becomes law, mining companies will have to pay about $\$ 11 \mathrm{bn}$ Australian dollars ( $\$ 10.8 \mathrm{bn} ; £ 6.9 \mathrm{bn})$ in charges in the first three years of the tax."(BBC News, 2011)

On 2 July 2010, The Australian reported: "Today, the Gillard Government is proud to announce a breakthrough agreement on improved resource tax arrangements that addresses the concerns of the resource industry.The new tax arrangements will underpin major economic reforms that will strengthen our economy so we can move forward together with confidence.”(Australian, 2010) This Minerals Resource Rent Tax bill would tax profits on mining in Australia; the bill had passed the senate and went into law in 2012.

BBC News reported:"Demand from emerging economies, such as China, has driven up the price of Australia's 
iron ore and coal.The Australian Senate has pushed through into law a $30 \%$ tax on iron ore and coal mining companies. The tax will raise A $\$ 10.6 \mathrm{bn}(\$ 11.2 \mathrm{bn}, £ 7 \mathrm{bn})$ over three years from major companies including BHP Billiton, Rio Tinto and Xtrata. Strong demand for raw materials from China and India has led to a resource boom in Australia.The mining tax is aimed at distributing the benefits of that revenue to other segments of the economy." (BBC News, 2012)

However a change in government -- previously led by Labor in 2012 to one led by Conservatives in 2014 -resulted in the repeal of the tax.BBC News reported:"Australia's previous Labor government had levied a mining tax to raise funds.Australia's current government has repealed a controversial mining tax after striking a deal with business tycoon Clive Palmer's political party.The 30\% tax on mining profits on coal and iron ore was first introduced by the former Labor government in 2012. The country's Senate voted to remove the mining tax, and the bill is now heading to the House of Representatives where it is expected to pass as well.Mr. Palmer's party had agreed to the move in return for certain concessions. This includes freezing the government's contributions to state pensions and keeping a bonus program for school children. The Palmer United Party - set up by the mining magnate last year - holds the balance of power in Australia's senate.Prime Minister Tony Abbott and his centre-right cabinet have been looking to get rid of the unpopular mining tax.Australian mining billionaire Clive Palmer has become a powerful politician.Large mining firms such as Fortescue Metals Group and Xstrata had also opposed the so-called Mineral Resources Rent Tax (MRRT), saying it hurt their competitiveness and affected future investment in the sector.'(BBC News, 2014)

Figure 4 shows the head of the Palmer United Party in 2014.

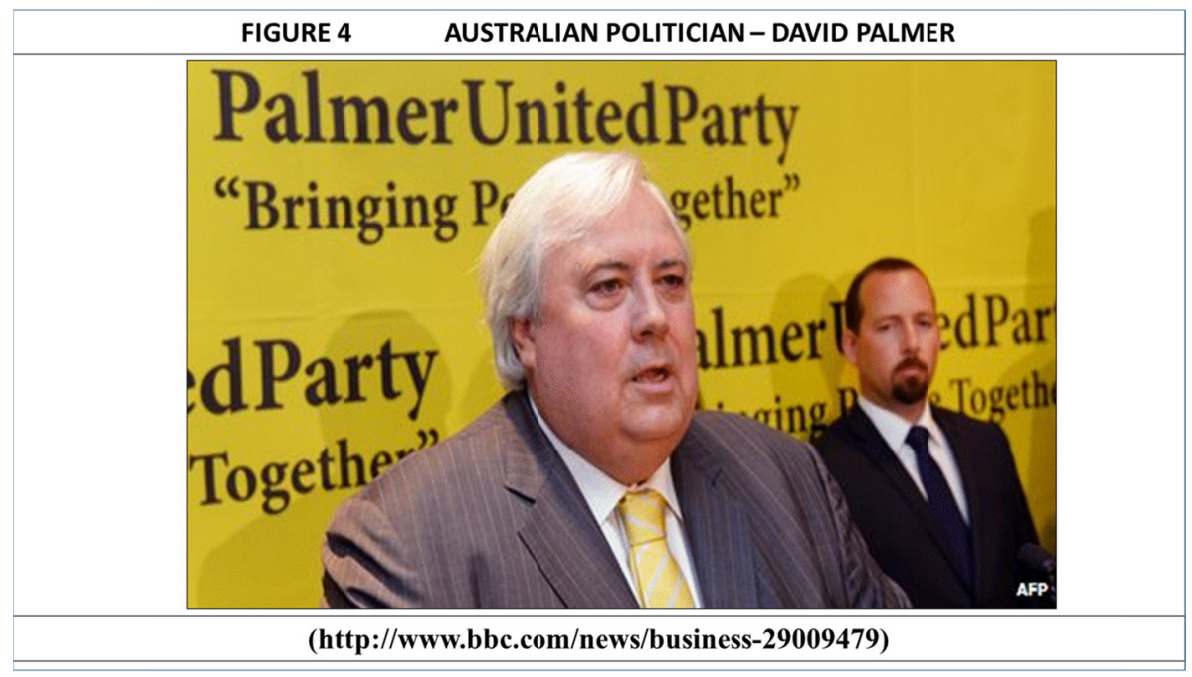

Figure 4. Australian politician- David Palmer

Due to the increasing demand for iron ore in Asia before 2012, the quantity $\mathbf{P}_{\mathbf{I}}$ of iron ore mined in Australia had been increasing.However, after the passage of the mining tax in 2012, the companies might have considered decreasing the quantity $\mathbf{P}_{\mathrm{I}}$ mined -- because mining companies did not like paying the additional tax.Next, after repeal of the tax, $\mathbf{P}_{\mathbf{I}}$ might be expected to again grow (as long as Asian demand increased).Thus the stasis of the mining industry in Australian could be impacted by the mining executives' dislike of the increased taxes on the industry.It was a mine owner, Clive Palmer, who organized a political party focused upon repeal of the tax.

In this Australian case, there was a temporal change to the economy and environment due to the passage and repeal of the mining rent tax.How can one model this temporal change, explaining the 'how and way' of it? One needs to go 'outside' of the integrated Leontief model, in order to model political decisions in a society, such as Australia.For this, one needs another methodology for modeling societal decision-making events -- historical events.This requires a complete change in modeling methodology from a tensor equation of Leontief's input-output model of a regional economy.

\section{Methodology - Analysis of Australian Societal Events}

We next we review how to model a societal event, 'change-event' in a society, such as the changes in taxation policy in Australia.One can analyze any historical event in a society within the methodological framework of a societal perceptual space.(Betz, 2010)Using this methodological approach, social science generalizations can be 
formally abstracted from and across different historical events, with their very different particularities and contexts.One learns about 'nature' from research, and the research must be performed under a proper 'methodology'.To learn about social theory from the empirical evidence in history, one needs to research history under proper, systematic methods.Empiricism in the social sciences requires the studies from history, but not just in any way.Proper social-science empiricism requires studying history systematically, as if a historical epoch was a kind of experiment -- an experiment in human society.Proper theory construction requires the abstraction of forms from experiments as theoretical principles -- theory which is generalizable and verifiable across all similar experiments.

The concept of a perceptual space, as a general way to observe nature, comes from the physical sciences.A perceptual space of physical space and time provides a common research framework for observation in all the physical and life sciences (e.g. physics, chemistry, biology).Formally, all physical events are perceived (observed and described) in a space-time framework.A three-dimensional geometric space X,Y,Zin which any physical object is described at a given time $(\mathrm{t})$ as residing at a point described by the three coordinates $(\mathrm{x}, \mathrm{y}, \mathrm{z})$.Objects can change positions in space $(\mathrm{x}, \mathrm{y}, \mathrm{z})$ through motion; and so time $(\mathrm{t})$ is used formally as a fourth dimension to enable the description of motion. The complete physical perceptual space description of point $\mathrm{X}$ of any physical object is thus given in the notation with four descriptive values as $\underline{X}=(\mathrm{x}, \mathrm{y}, \mathrm{z}, \mathrm{t})$. This is the observational framework for the environmental modeling of physical processes.

For observing a societal event, one needs an analogy to this -- a societal perceptual space.One has been constructed from the three basic dichotomies in sociology: individual-society, groups-processes, and reason-action. (Betz 2011)

The first basic idea in the sociological literature is how one can distinguish between individuals and the society in which the individuals live -- the dichotomy of individual \& society. The second basic idea in sociology (and in organizational theory) distinguishes within a society how individuals associate into groups within a society and the processes a group inculcates in its members -- the dichotomy of group \& process. A social process is a series of actions coordinated to produce an outcome planned by a group. In describing societies, sociological literatures use the basic descriptors of groups and organizations as societal objects and of processes (social processes) performed by groups or organizations. The third basic idea found in the sociology (and in economics and in management science) is about individuals and their rational behavior in society.Individuals described as sentient (or cognitive) beings acting according to perceived reasons -- the dichotomy of action \& reason. One can graphically show these three basic social science dichotomies upon a three-dimensional societal space, as shown in Figure 5.

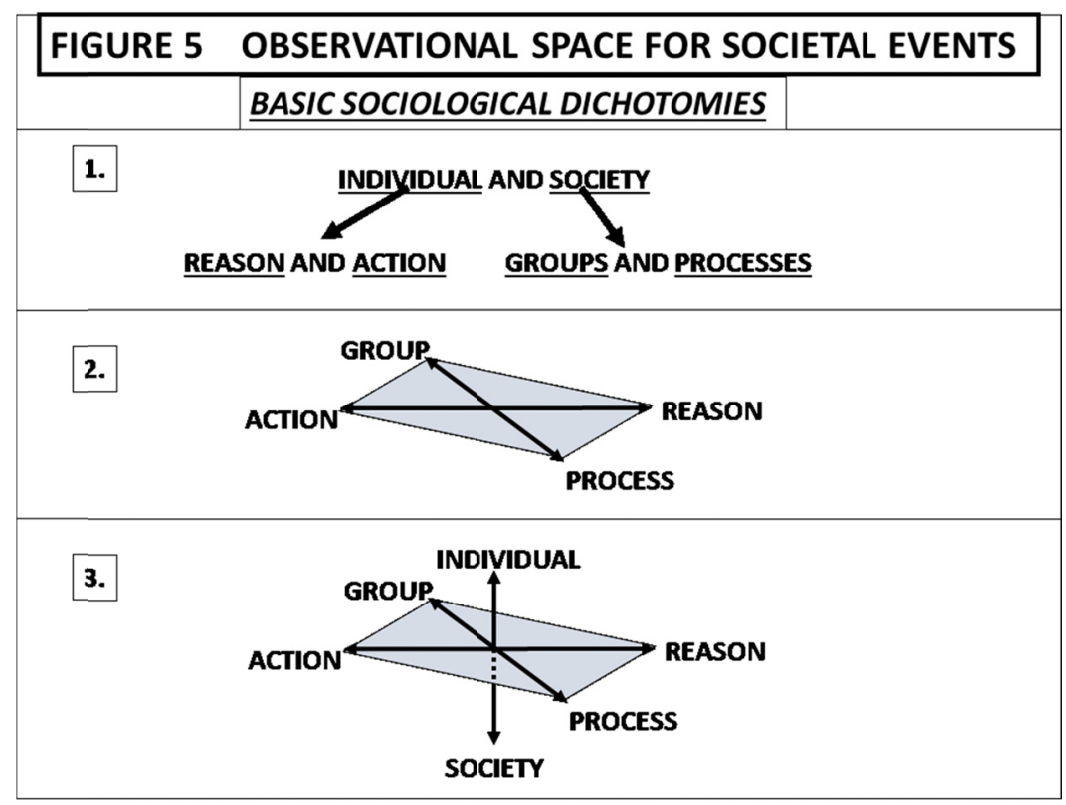

Figure 5. Observational space for societal events

Thus in any historical set of events describing an epoch of a society, an event can be described as factors and interactions of the three dichotomies of observation. To conveniently inscribe events in the perceptual space, one 
can show the areas around the dimensional axes as a kind of event box, Figure 6.

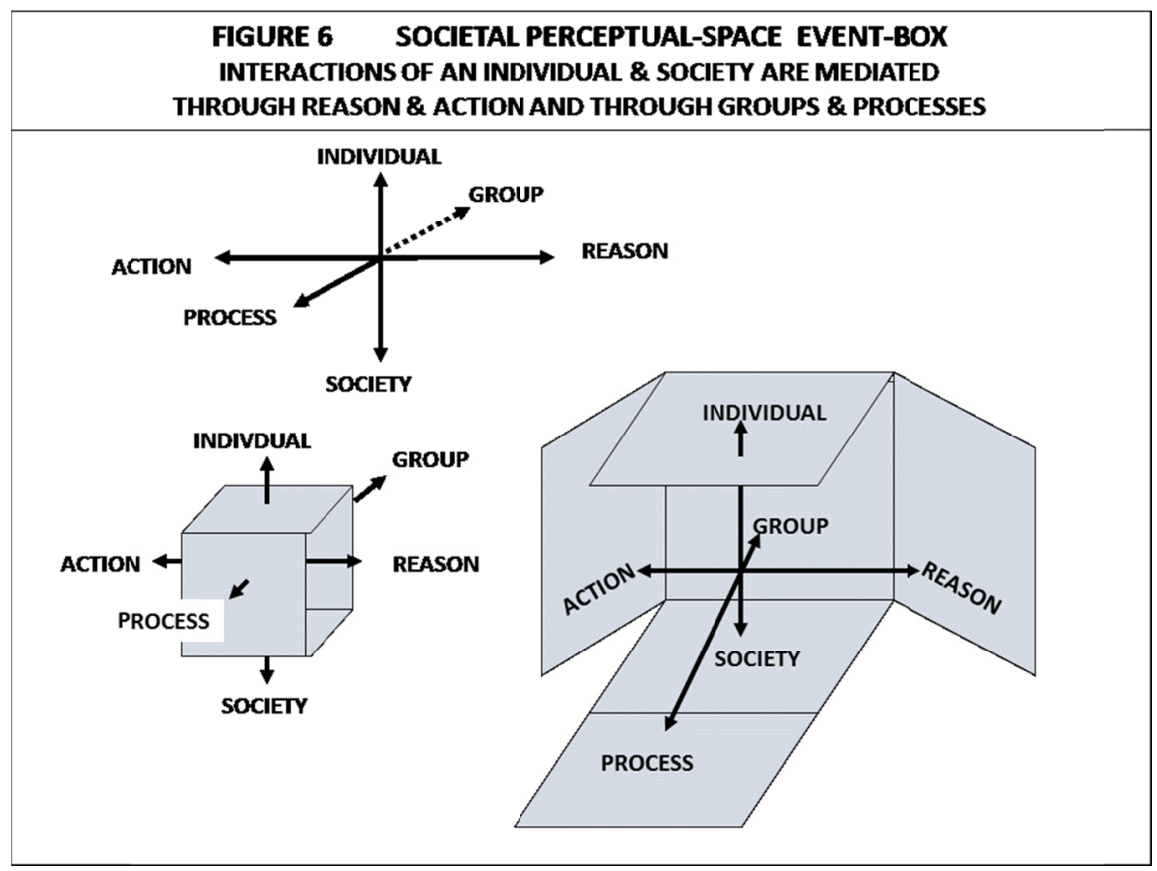

Figure 6. Societal perceptual-space event-box

This "open-box" form can allows one to inscribe the significant factors which occur in an historical event. We can now analyze the Australian Mining Tax Event in this observational framework, Figure 7.

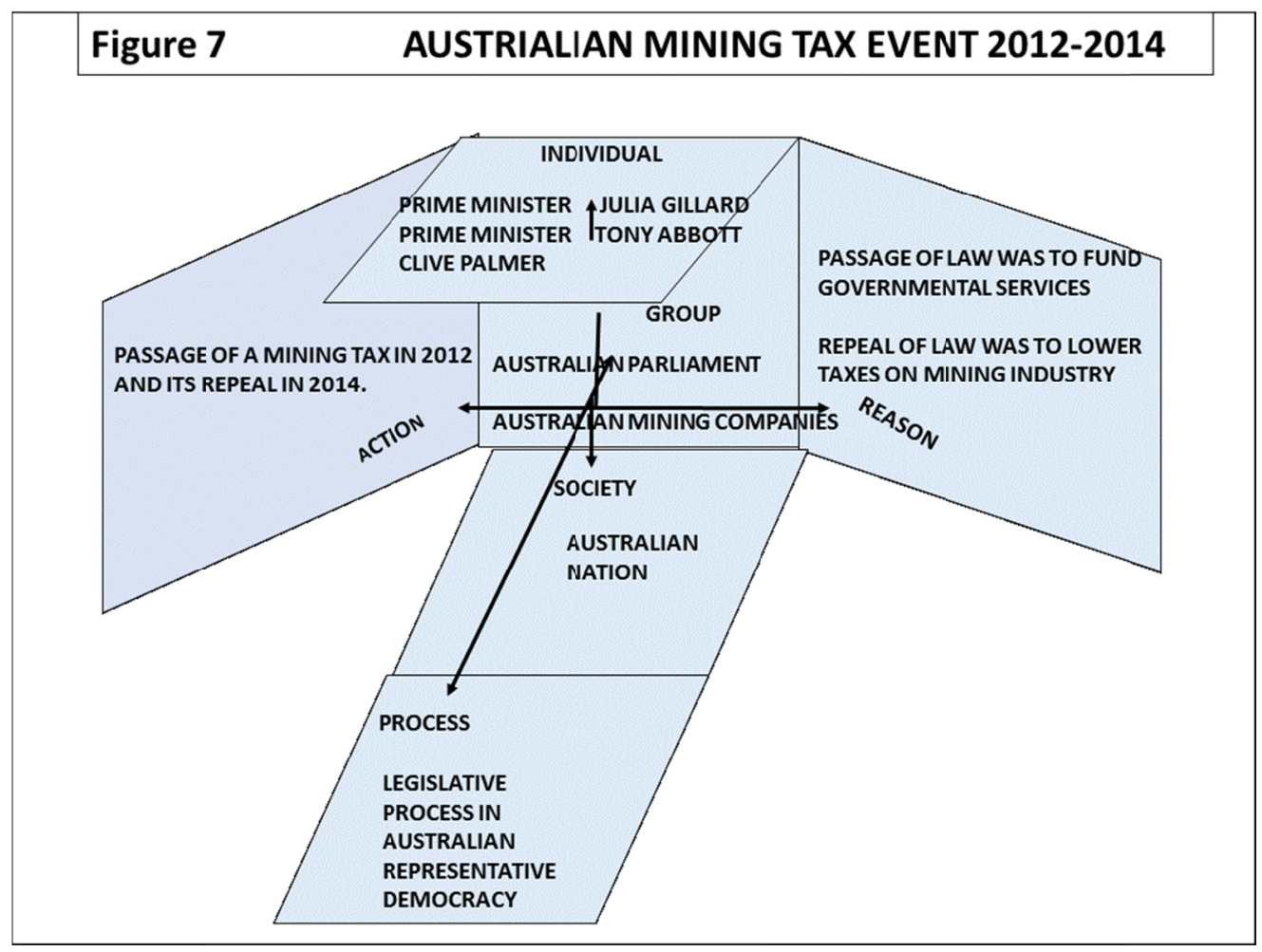

Figure 7. Australian mining tax event 2012-2014

ACTION - The actions were the government passing a mining tax in 2012 and its repeal in 2014. 
REASON -The reasons for the passage by the labor government in 2012 was to fund services; and the reason for its repeal in 2014 by the conservative government was to lower tax burden on the mining industry.

GROUP -- The groups involved were the Australian parliament and the Australian mining companies.

PROCESS - The process was the democratic procedures of making laws in the Australian nation.

SOCIETY - The society was the Australian nation.

INDIVIDUALS - The individuals involved in the actions were the labor government leader Prime Minister Julia Gillard in 2012; and in 2104, the conservative government's Prime Minister Tony Abbott and the tycoon Clive Palmer's political party.

Next we review how explanation occurs in a societal event, in order to analyze the explanations for the two Australian events of passage and repeal of the mining-rent tax.Modeling a natural thing (object of nature) requires both a description of a thing and also explanation of the dynamics of a thing. The observational space of a societal event analytically describes the event but does not explain it.For explanation, one needs to expand the topology of the observational space, and this was done in the theory of societal dynamics, shown in Figure 8.

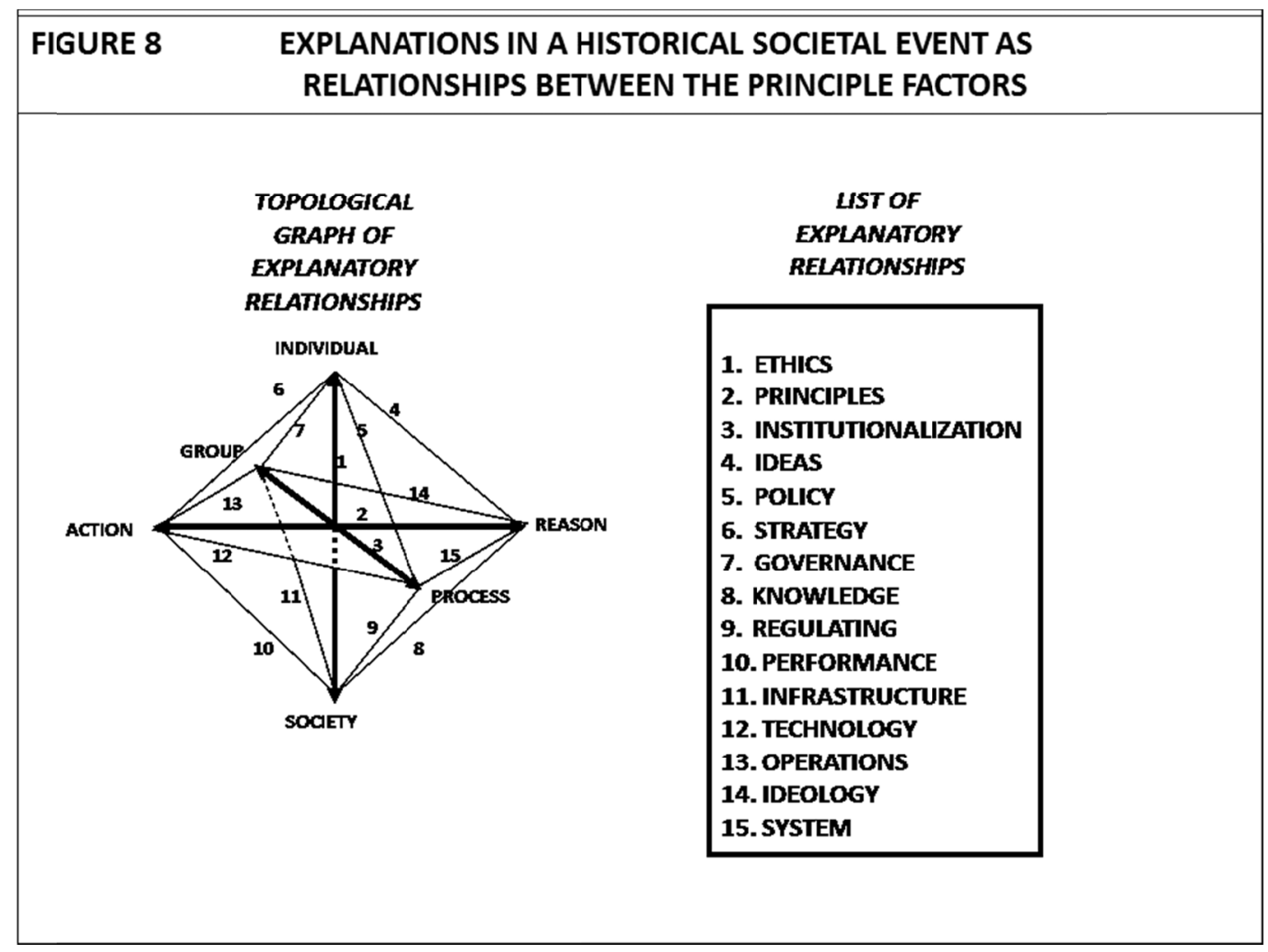

Figure 8. Explanations in a historical societal event as relationships between the principle factors

The six dimensional-points of the observational space can be connected by fifteen lines as a topological graph. Each graph relationship provides a kind of explanation connecting two factors. (Topology is a field of mathematics concerned the connectedness of geometrical forms, and topological graphs display this connectivity as lines connecting points in the geometrical form.) The societal dynamics event-graph displays the kinds of explanations which can connect the principle factors in a historical event, as fifteen kinds of explanations.(Betz, 2011)

There were two sequential events as the passage and repeal of the Australian 'Minerals Resource Rent Tax Bill'. Two pyramids of observational explanations in the societal observational space can be constructed about passage and repeal of the mining tax, Figure 9. 


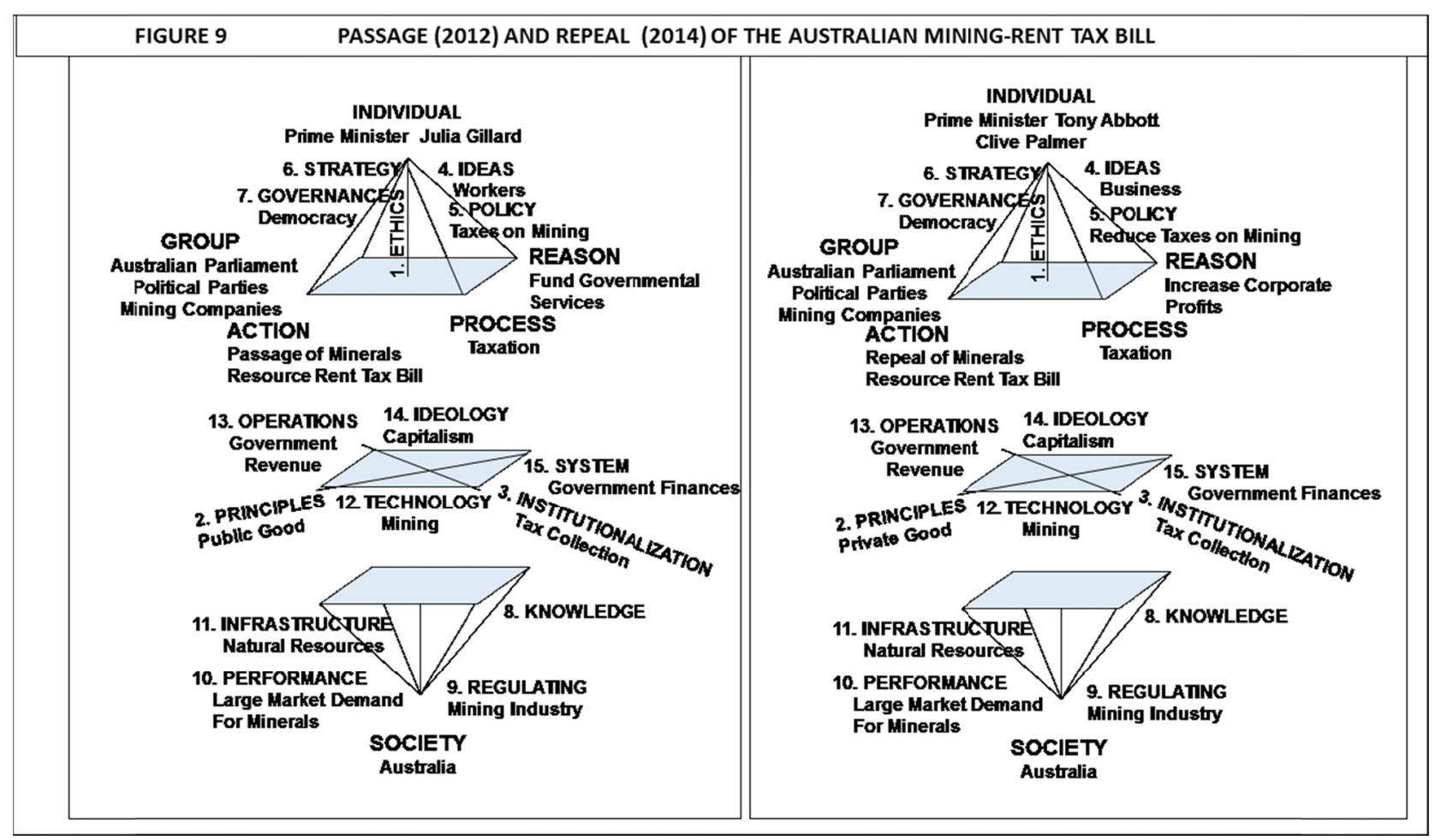

Figure 9. Passage (2012) and repeal (2014) of the Australian mining-rent tax bill

In the passage of the law, the key individual of Prime Minister Julia Gillard, head of the Labor Party.And in its repeal, the key individual was Prime Minister Tony Abbott, head of the Conservative Party.Clive Palmer, leader of Palmer United Party, aided the Conservative Party in passing the repeal.Thus the Group of Australian Parliament, Political Parties, and Mining Companies sequentially altered the economy and environment of Australia through first the passage and then the repeal of a government policy that impacted the Australian economy and environment.Their (4) Ideas differed.The Labor party thought about the benefits of the tax to the workers in Australia; while the Conservative party thought about the burden of the tax to the mining businesses in Australia.These ideas led to different (5) Policies, with Labor passing taxes and Conservatives repealing taxes.Both parties believed in (7) Governance by democracy, taking turns at forming a government as the result of Australian national elections.

For the socio-technical (15) System of government finances, both Labor and Conservative parties were focused upon (13) Government revenue. However their (2) Principles differed about the mining tax.The Labor party in the passage of the tax had emphasized the Public Good of "spreading the wealth"; whereas the Conservative party in the repeal of the tax had emphasized the Private Good of conserving the wealth of mining companies.

In the self-organizing system of Australian Society, the (11) Infrastructure of the society was focused upon the Natural resources of the country.At the time (10) Performance of the society was booming due to the increased Asian demand for iron ore.

We see in this analysis of the explanations for the passage and repeal events that what differed between the two political parties in their respective (7) Governance were (4) Ideas, (5) Policies, and (2) Principles.Thus cognition (thinking) in the political-economic plane of the Australian region impacted the environment of the region through a tax which discouraged wealth creation of the mining companies (passage) or encouraged wealth creation of the companies (repeal).

\section{Methodology: Dynamical Change in Australian Society}

We have two kinds of models: one for the stasis of economic/environmental processes (Tensor Leontief equations) and another for change in a society (societal event in societal dynamics).Yet phenomena depicted by these two kinds of models can impact each other.Societal events (such as the minerals rent tax) can impact economic/environmental processes (such as open pit mining activities).How can 'changes' in 'societal cognition' (societal event) and 'environmental processes' (economic/environmental processes) be connected together in a 
modeling 'ontology'?

For this connection between societal events and regional stasis, we next review how generally the dynamics of any society can be historically analyzed as 'change' and 'stasis'.Societal change can result in different societal structures, which impact the environmental region of the society. The methodology of perceptual space and societal models can describe successive societal conditions of change and stasis.One can imaginea meta-space to the societal change events and the stasis of a society (societal structure-function) between changes.(Betz, 2011)This is a meta-logic to the logic embedded in the idea of a perceptual space.In such a meta-perspective one can the change and stasis periods of a society upon a timeline of history, Figure 10.

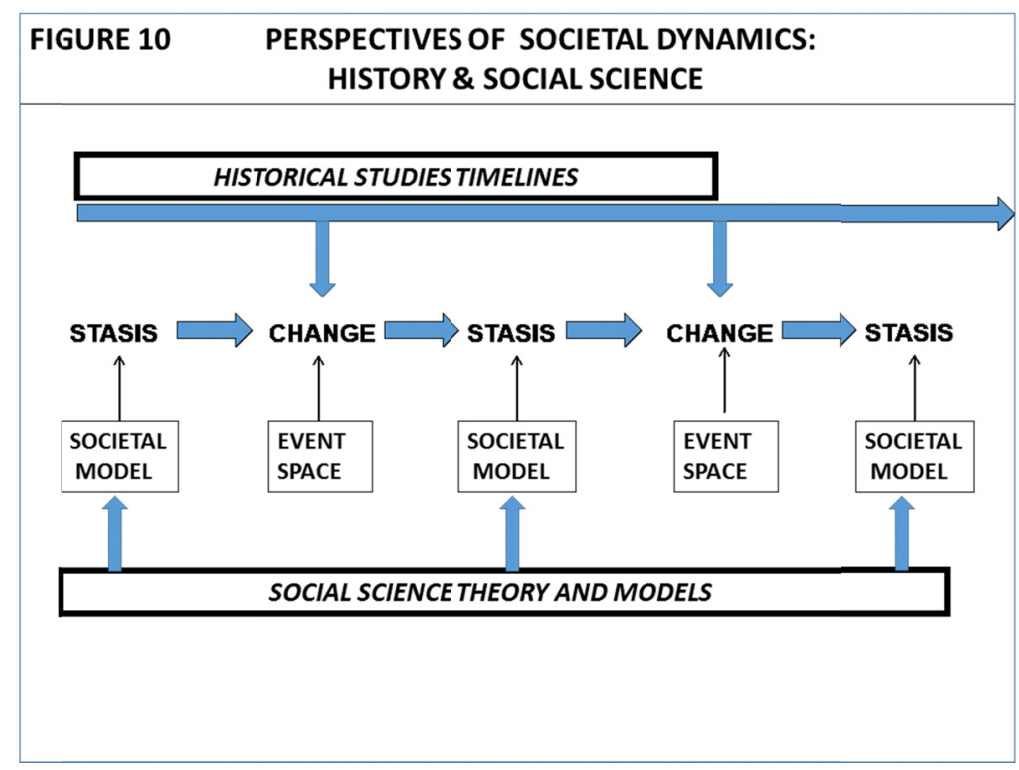

Figure 10. Perspectives of societal dynamics: history \& social science

When one observes the dynamics of a society in this way, one can see clearly an important relationship of the discipline of history to the discipline of the social sciences.Historians tell of the change in societies, whereas social scientists tell of the stasis in societies. Social sciences create theories of 'stasis' in societies -- stable social structures and processes existing in a society. History and the social sciences are complementary, telling the dynamical story of a society as successive 'change' and 'stasis'.In this way, the disciplines of history and the social sciences can be intellectually integrated as the description and theory of societal dynamics. Thus two kinds of models are needed to depict the history of a society:(1) a model of the stability of society (stasis model) and (2) a model of a change event (societal-change model).

We apply this analysis to the case of Australian mining-rent tax. There were three successive stasis periods: before the tax, after the tax, after repelling the tax. There were two change events: passage of the tax in 2012 and repeal of the tax in 2014. We can place the analyses of the two change events on a societal dynamics recent history for Australian government, Figure 11. 


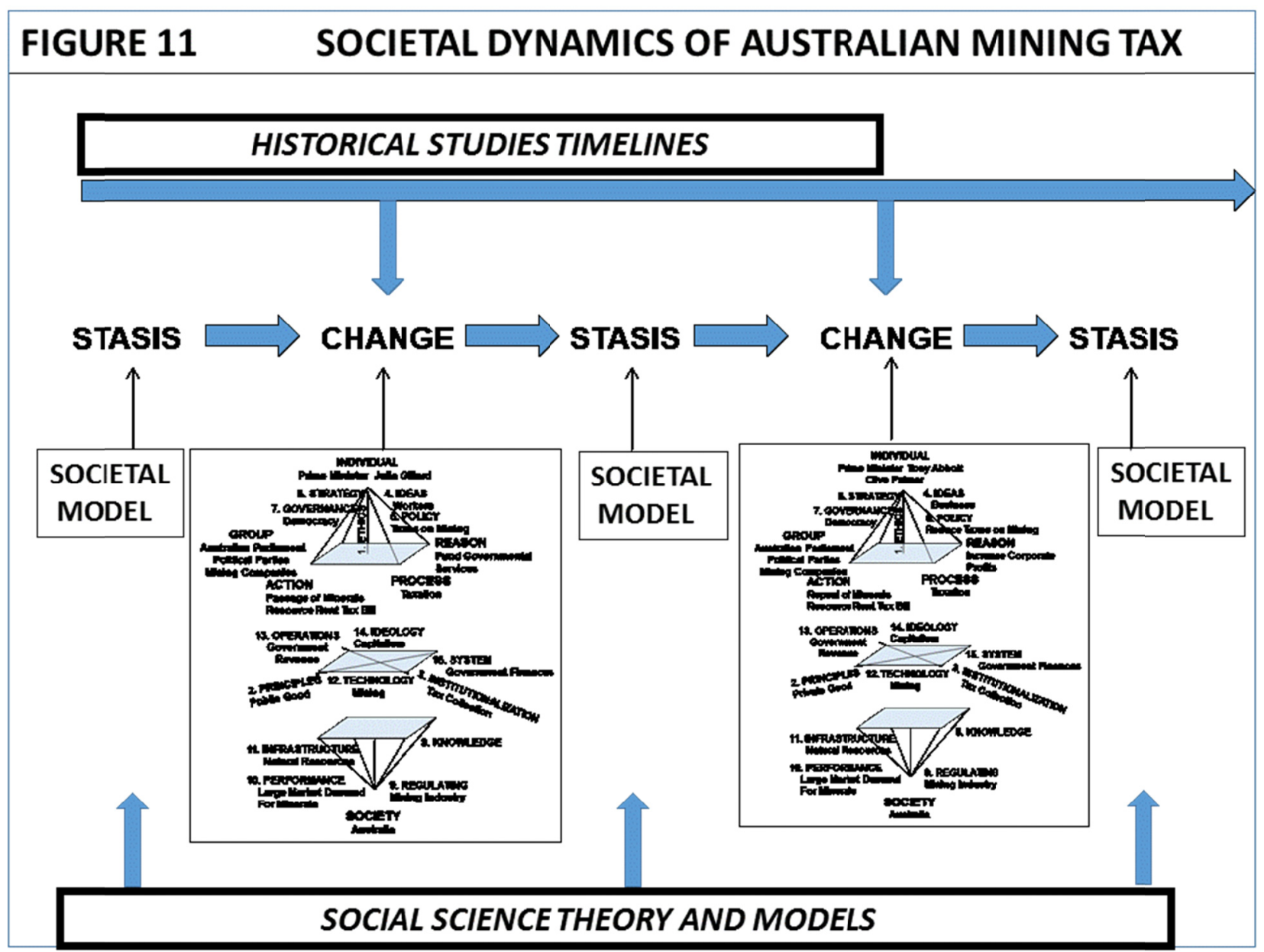

Figure 11. Societal dynamics of Australian mining tax

We see that in this meta-model framework of a society-historical timeline that change events in a society can alter the steady-state operations (stasis) of the society.The passage and repeal of the Australian mining-rent tax impacted the economics of the society because mining is a major segment of the economy and has a major impact upon the environment of the region. One can next add the stasis models of the Australian economic-environmental region (from Figure 2). This is next shown in Figure 13, of the meta-model framework of recent Australian societal dynamics. 


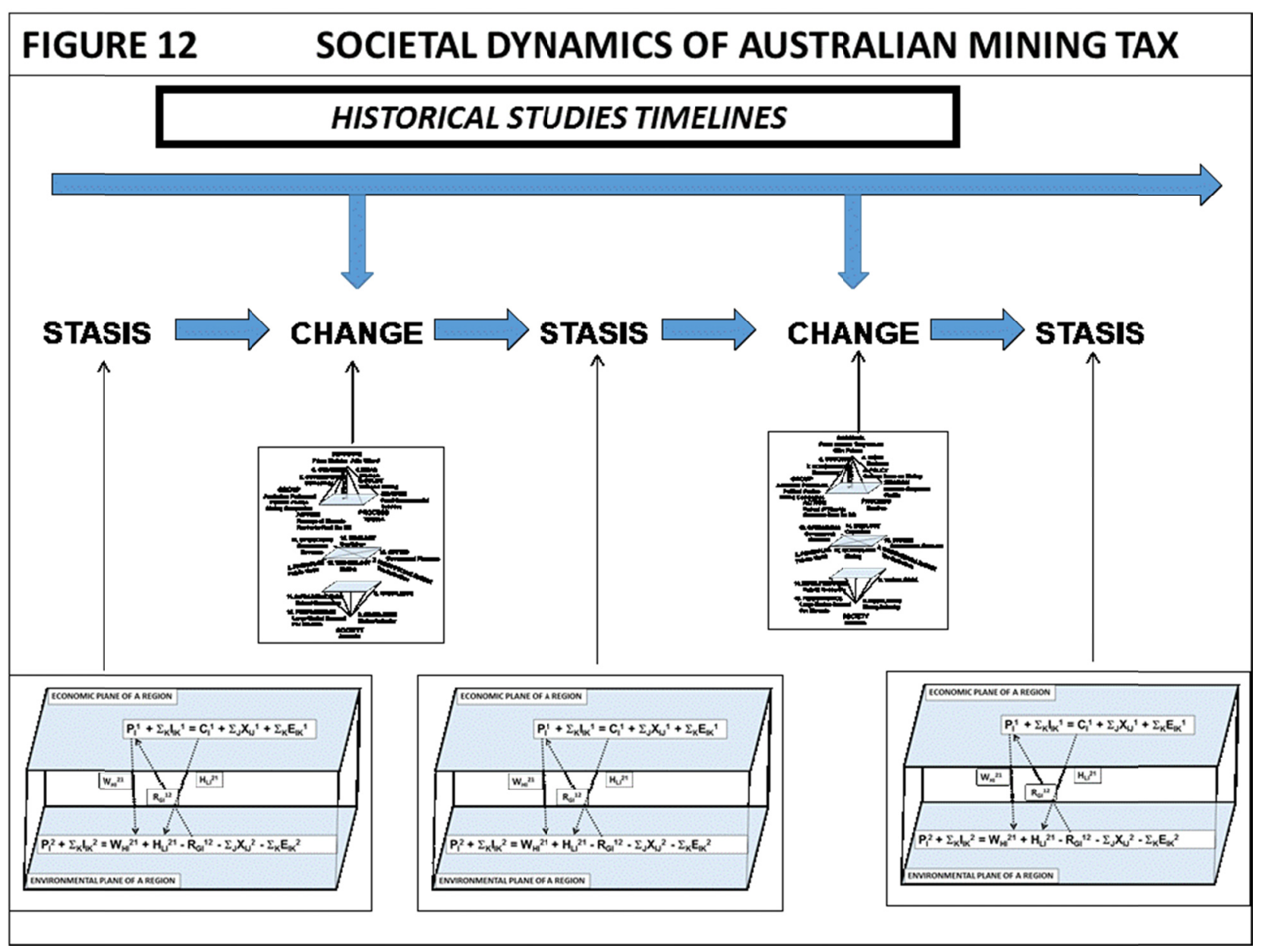

Figure 12. Societal dynamics of Australian mining tax

Historically in Australian society in 2012 and 2014, the two change-events of the 'passage' and 'repeal' of the mining tax could have altered the quantities of the economic production of mineral ores in Australia.Events which alter the policies and operations of societal systems that change the environment also impact the environmental region of a society.

By the model ontology of 'societal historical time-lines', one can inscribe relevant information (1) about the economic activities and environmental processes in the region of a society and also (2) about societal policies and events which can alter the region.

Two kinds of information about a societal region can thus be brought together, information about the stasis of a society and information about changes in societal stasis.

\section{Historical Case: Malay's Iron Hill}

The impact of mining upon the environment is a global issue, not just isolated to Australia.For example about mining operations in 2014 in Indonesia, Keith Bradsher wrote: "Giant mining equipment has stripped away the palm trees and other vegetation from a jungle bluff here with a Malay name that translates to "Iron Hill." Huge power shovels gouge long furrows down cliffs of fuchsia clay, scooping out the shiny black iron ore at their base.The mine here operates round the clock, seven days a week.The Chinese-controlled CAA Resources, which reopened the dormant mine early this year, has rapidly ramped up production to an annual rate of 500,000 tons, with plans to double it by next year.Its ambitions, though, are being undermined by the shifting global terrain: Iron ore sells for less and less these days. 'China still needs a lot of steel for infrastructure, housing projects and rails," Li Yang, CAA's chairman and chief executive, yelled as ore-processing machinery clanked noisily nearby. "The only problem is the pricing.'With seemingly insatiable demand from China, the price of iron ore, along with many other commodities, soared for most of the past decade. China manufactures half the world's steel, which is made from iron and used for housing construction, rail lines, car making and more. The boom helped 
support the rapid growth of companies like CAA, as well as the economies of developing countries rich with resources. From Indonesia and Australia to Peru and Brazil, multinationals and Chinese companies embarked on large-scale, long-term investments in mines." Bradsher, 2014)

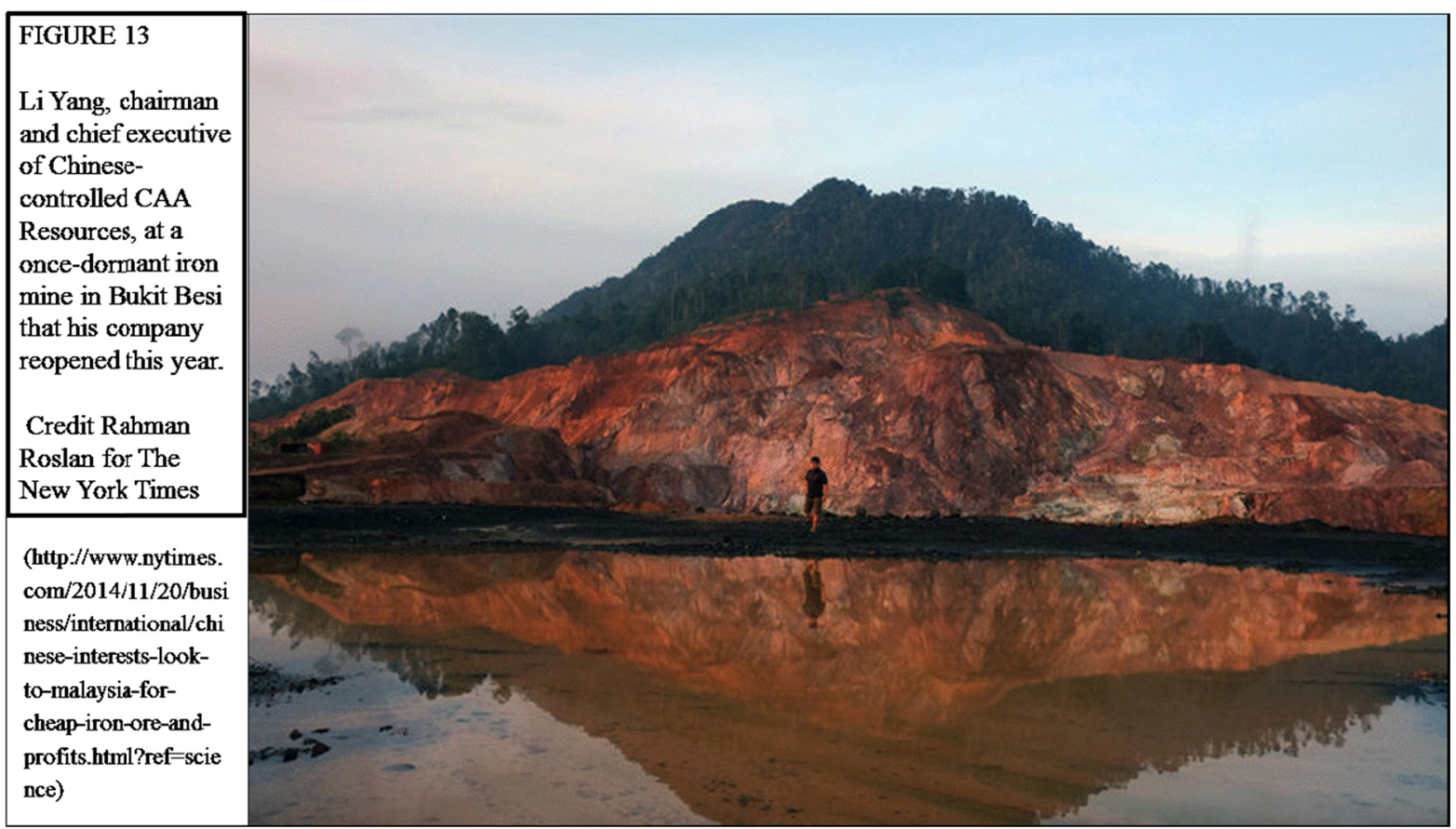

Figure 13.

The connections between the mining of resources and the societies controlling the resources is universal.About the history of the 'Iron Hill' mine, Bradsher wrote: 'CAA Resources has been at the center of the push here, reopening Malaysia's most famous mine. Discovered in the jungles of eastern Peninsular Malaysia in 1916 by a Japanese geologist, Bukit Besi became one of the world's largest mines as it supplied the Japanese steel industry through World War II.The British seized the mine as war spoils after Japan's surrender and handed it over to a British company. The British mining company initially struggled with Communist insurgency attacks on its rail lines, including bombings that destroyed three train stations, but nonetheless became a big supplier of ore for Japan's postwar industrial revival.Then, in 1971, the mine closed because of what a historic marker here describes as bureaucracy and labor union troubles. The site sat idle for most of the next four decades.Learning from the mistakes of his predecessors, Mr. Li, the 27-year-old CAA chief and scion of a Chinese family that had grown wealthy in the mainland iron ore industry, immediately worked to build ties with local and national political leaders, as well as with Malaysian royalty."(Bradsher, 2014)Figure 14 lists the societal time line of these events.

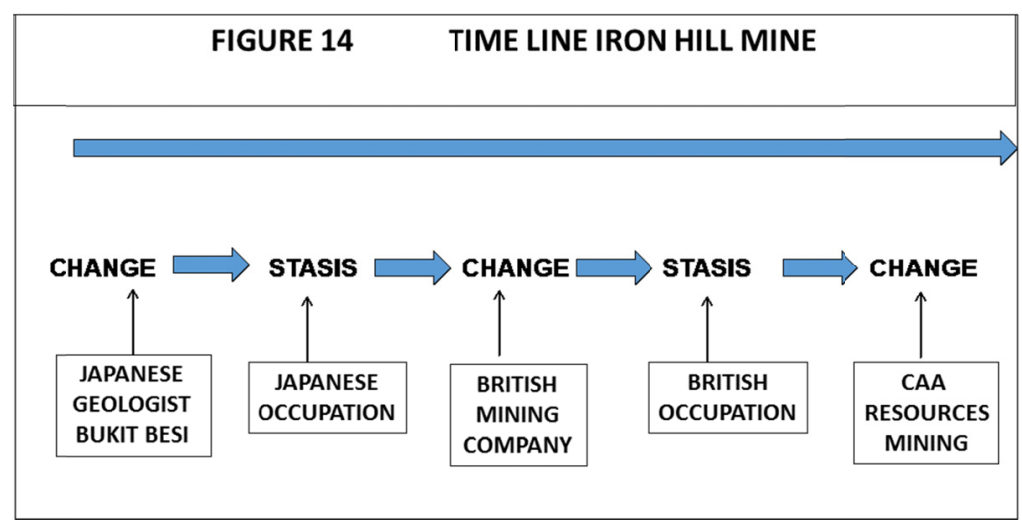

Figure 14. Time line iron hill mine 
Bradsher elaborated upon the societal arrangements about the mine after CAA Resources reopened the mine:"Mr. $\mathrm{Li}$, who owns 56 percent of CAA, said that he had paid for each of the ruling party politicians with indirect stakes in the mine to receive the royally granted title of "dato," which roughly translates as "the honorable." It costs about $\$ 100,000$ to arrange each royal grant, he said.Although anti-corruption groups have campaigned against such arrangements, particularly indirect stakes, Mr. Li said he was simply following common practices in Malaysia. A government-linked industry group in Beijing announced plans on Oct. 24 to introduce standards for Chinese companies in areas like labor rights, environmental protection and community relations.To avoid potential labor issues, Mr. Li has largely imported workers, who are not unionized. CAA Resources brought in about 40 mining engineers, accountants and other professionals from China, and filled the rest of its work force with laborers from low-wage countries like Cambodia, Myanmar and Vietnam. The workers are on 12-hour shifts, up to seven days a week, and are paid based mostly on how much iron ore each shift can produce, Mr. Li said.Pacing across the jungle mine, Mr. Li described his recruitment pitch to potential hires. "You can save a lot of money, there is nothing to do here," he said, "I say, "Each of you will be a hero, you will take back 100 percent of your savings, your wife will be happier, your children will be happier.' "He has avoided filing an environmental-impact statement by erecting an eight-foot-high, blue corrugated-steel fence across the middle of the site with a gate, and calling it two mines, each less than 500 acres. Only mines over 500 acres require environmental approval." (Bradsher, 2014)

Here we see that the activities in a society by individuals working in societal conditions can alter both the economics and the environment of a society.In this case, the mining company did not provide employment to citizens of the region, nor did it take responsibility for the environmental impact of its activities. Surely these two policy concerns of the Malay society could be addressed if a model for a sustainable Malay economy were constructed and used for policy. Instead, in this case, economic/environmental policy had been made principally by royally granted titles of 'dato'.

\section{Results and Conclusion}

The methodology we are using in this paper focuses upon developing and applying modeling techniques to historical cases of societal stasis and change.This modeling approach allows one to model the societal decision-making events which directly impact economic-environmental conditions.Because the Australian mining-rent tax was in place so short a time, it did not have much impact upon the Australian landscape.But had it been in place longer, it likely would have discouraged investment for mining expansion, thereby slowing the expansion of the open-mining pits. However, the model does show how modeling can connect the political-economic decisions to the economic-environmental activities of a society - policies for sustainable economies.

The model ontology of 'societal historical time-lines' facilitates policy modeling for sustainable economies through collecting and storing relevant information about (1) economic activities and environmental processes in the region of a society and also (2) policies and events in the society which can alter the region.

\section{References}

Australian. (2010). Full statement and detail of new mining tax.The Australian.RetrievedJuly 2, 2010,fromhttp://www.theaustralian.com.au/archive/politics/full-statement-and-detail-of-new-mining-tax/sto ry-e6frgczf-1225887000521?nk=c3c25be566406bc4b1640aaa1e598cf1

BBC News. (2011). Australia mining tax clears hurdle, after much debate. Retrieved November 23, 2011, from http://www.bbc.com/news/business-15849226

BBC News. (2012). Australia passes controversial mining tax into law. Retrieved March 20, 2012, fromhttp://www.bbc.com/news/business-17441170

BBC News. (2014). Australia's mining tax repealed. Retrieved September 2, 2014, fromhttp://www.bbc.com/news/business-29009479

Betz, F. (2011). Societal Dynamics. New York, Springer.

Betz, F. (2013).Modeling Sustainable Economy: Integrating Economic, Environmental, and Population Models.International Journal of Innovation and Technology Management, $10(1)$. http://dx.doi.org/10.1142/S0219877013500077

Betz, F., \& Phillips, F. (2012). Models-Talking-To-Models for Policy.PICMET 2012 Conference Proceedings.

Bradsher, K. (2014). Chinese Interests Look to Malaysia for Cheap Iron Ore and Profits. New York Times. Retrieved 
fromhttp://www.nytimes.com/2014/11/20/business/international/chinese-interests-look-to-malaysia-for-chea p-iron-ore-and-profits.html?ref=science

Reedaug, S. (2014).Rio Tinto Profit Doubles, Helped by Aluminum and Copper. Retrieved August 7, 2014, fromhttp://www.nytimes.com/2014/08/08/business/international/rio-tinto-profit-doubles-helped-by-aluminu m-and-copper.html

\section{Copyrights}

Copyright for this articleis retained by the author(s), with first publication rights granted to the journal.

This is an open-access article distributed under the terms and conditions of the CreativeCommons Attribution license (http://creativecommons.org/licenses/by/3.0/). 